\title{
A EVOLUÇÃO QUÍMICA DAS ÁGUAS SUBTERRÂNEAS DE POÇOS DE CALDAS - MG
}

\author{
WALDEMIR B. CRUZ* \& CARLOS A. M. PEIXOTO*
}

\begin{abstract}
GROUNDWATER CHEMICAL EVOLUTION OF POÇOS DE CALDAS - MG. The chemical evolution and the origin of the groundwater, cold and thermal springs composition are analysed related, to the geochemical environment of the Poços de Caldas alkaline complex. The thermal waters origin are related to a large and deep open fracture system in three main directions: N14E, N50E and E-W. The tritium content when simultaneously analysed with the deuterium and oxygen-18 set show that thermal waters are old meteoric waters (30 - 40 years of age). On the other hand, the cold springs that circulate on the superficial levels are more recent, which is a characteristic of an acid oxidizing environment without sulfldes and greater concentration of free $\mathrm{CO}_{2}$ and $\mathrm{Rn}^{222}$. The $\mathrm{pH}$ increases slowjy with depth and also the $\mathrm{HCO}_{3}^{-}, \mathrm{Na}^{+}, \mathrm{SO}^{2-}{ }_{4}$ and the $\mathrm{SiO}_{2}$ content. High concentrations of fluorides follow this process. Reducing environment with an increase in the sulphide content and a decrease in radioactivity are trends in the system studied.
\end{abstract}

Keywords: Groundwater, geochemical evolution, thermal waters, Poços de Caldas, Minas Gerais.

RESUMO A evolução química e a origem dos constituintes das águas subterrâneas, incluindo as nascentes, fontes frias e as fontes termais, são analisadas com base no ambiente geoquímico prevalecente no Complexo Alcalino de Poços de Caldas. A origem das águas termais está relacionada a um extenso e profundo sistema de fraturas abertas, do qual foram identificadas três direções principais: N14E, NSOE e E-W. Os conteúdos em trítio, analisados em conjunto com deutério e oxigênio-18, mostram que as águas termais são meteóricas antigas, com idade superior a 30 - 40 anos, ao contrário das fontes frias de circulação superficial, que são águas recentes, características de um ambiente oxidante, ácido, com ausência de sulfetos e maior concentração de $\mathrm{CO}_{2}$ livre e $\mathrm{Rn}^{222}$. Com o aumento da profundidade, ocorre lenta e progressiva elevação do $\mathrm{pH}$, enriquecimento em $\mathrm{HCO}_{3}^{-}$ $\mathrm{Na}^{+}, \mathrm{SO}_{4}^{2-}$ e $\mathrm{SiO}_{2}$, acompanhados de alta concentração de $\mathrm{F}$. As águas tendem para um ambiente redutor, apresentando aumento de sulfetos e decréscimo de radiatividade.

Palavras-chaves: Águas subterrâneas, evolução geoquímica, águas termais, Poços de Caldas, Minas Gerais.

INTRODUÇão A Fundação Centro Tecnológico de Minas Gerais realizou uma série de estados e levantamentos hidrogeológicos para a Prefeitura Municipal de Poços de Caldas, com o objetivo de identificar os principais sistemas aqüíferos, os aspectos relacionados à qualidade das águas e as possibilidades de contaminação e poluição dos recursos hídricos subterrâneos.

Os trabalhos foram desenvolvidos entre novembro de 1986 e setembro de 1987 e a área estudada abrangeu toda a bacia do Ribeirão das Antas, com maior detalhamento da área em torno de Poços de Caldas.

Os principais aspectos hidrogeológicos da área foram apresentados por Cruz \& Peixoto (1989). Neste trabalho, são apresentados os resultados do estudo hidroquímico, com ênfase para os aspectos relacionados à evolução físico-química das águas e a origem dos constituintes.

METODOLOGIA O desenvolvimento dos trabalhos processou-se por meio das seguintes etapas e procedimentos metodológicos:

- Pesquisa bibliográfica e coleta de dados

- Análise preliminar dos dados

- Fotointerpretação

Efetuada sobre aerofotos na escala 1:60.000 do vôo AST10, 1964-66, a fotoanálise teve por objetivo identificar as principais feições geológico-estruturais de interesse à ocorrência das águas subterrâneas, com ênfase para o mapeamento do sistema de fraturamento da área estudada.

Trabalho de campo Desenvolvido em duas etapas, realizadas em novembro de 1986 e em fevereiro de 1987, os trabalhos de campo corresponderam à execução das seguintes atividades:

- Observações gerais sobre a geologia e petrografía da área, tendo por base o Mapa Geológico, na escala 1:50.000, elaborado pela CNEN-NucleBrás (1975).

- Inventário de pontos de água, incluindo o levantamento de dados sobre fontes e poços tubulares existentes.

- Amostragem de águas subterrâneas de fontes e poços tubulares e de águas superficiais em locais de interesse.

- Análise, processamento e interpretação de dados.

- Tratamento e interpretação dos dados de análises químicas, incluindo os maiores elementos, metais e outros elementos traços, e composição isotópica das águas - deutério, oxigênio-18 e trítio. As análises físico-químicas foram realizadas pelo Departamento Municipal de Água e Esgoto (DMAE) de Poços de Caldas (análises parciais), pelo CETEC (análises de metais), enquanto as análises isotópicas foram realizadas pelo Centro de Energia Nuclear na Agricultura (CENA), de Piracicaba (deutério e oxigênio-18) e pelo Centro de Desenvolvimento da Tecnologia Nuclear - NUCLEBRÁS, em Belo Horizonte (trítio).

OCORRÊNCIA E DISTRIBUIÇ̃̃O DAS ÁGUAS SUBTERRÂNEAS A Bacia das Antas é constituída por rochas intrusivas (foiaitos e tinguaitos) e por rochas vulcânicas (fonolitos, tufos, brechas e aglomerados associados) pertencentes ao maciço alcalino de Poços de Caldas.

Tanto as rochas plutônicas quanto as vulcânicas são densas, compactas, não-porosas, pouco permeáveis, com capacidade aqüífera muito reduzida. As possibilidades de armazenar e transmitir a água dessas rochas variam com seu grau de 
meteorização e de fraturamento. Hão há aqüíferos granulates superficiais de importância, predominando na área os aqüíferos em meio fraturado, onde a ocorrência de água subterrânea é condicionada aos sistemas de fraturamento das rochas.

No interior do planalto, grande número de falhas e fraturas corta todo o complexo e prolonga-se pelas encaixantes (granitos e gnaisses do embasamento). As fraturas de grande extensão (maior que $2 \mathrm{~km}$ ) mostram direções predominantes $\mathrm{N} 30^{\circ}-60^{\circ} \mathrm{E}$ e $\mathrm{N} 30^{\circ}-60^{\circ} \mathrm{W}$. As fraturas de pequena extensão mostram maior dispersão na sua orientação, destacando-se como direções preferenciais, as $\mathrm{N} 10^{\circ}-20^{\circ} \mathrm{E}$ e $\mathrm{N} 40^{\circ}-50^{\circ} \mathrm{W}$.

Uma efetiva circulação das águas subterrâneas é evidenciada pela quantidade de fontes, exutórios e nascentes, localizadas nas cabeceiras de drenagem. Quase todos os afluentes do Ribeirão das Antas têm suas nascentes alimentadas por restituição das águas subterrâneas. A restituição subterrânea aos rios é muito elevada, tratando-se de uma bacia constituída de rochas magmáticas e de solo predominantemente argiloso, o que demonstra o elevado grau de fraturamento das rochas. A análise do hidrograma, correspondente a um ano médio do posto fluviométrico da Usina Poços de Caldas, mostrou que do escoamento superficial total de $1.215 \mathrm{~mm}$ cerca de $452 \mathrm{~mm}$ correspondem ao escoamento subterrâneo. Esse valor, relacionado ao total de chuva anual, fornece uma estimativa da taxa de infiltração na bacia da ordem de $27,6 \%$. O balanço hídrico anual, na média aproximados, é expresso pela seguinte equação: Precipitação (100\%) - Evapotranspiração (40\%) + Escoamento total $(60 \%)$

Além das nascentes difusas, as águas subterrâneas ocorrem ainda através de certo número de fontes pontuais frias ou termais, a maioria localizada na depressão de Poços de Caldas, o que permite identificar: 1. uma zona aqüífera rasa de pequena profundidade; 2 . uma zona aqüífera intermediária; e 3. uma zona aqüífera de circulação profunda. Às duas primeiras zonas estão relacionadas a maior parte das fontes frias e as águas exploradas através de poços tubulares; à última zona estão associadas as fontes termais.

As fontes frias pontuais são todas de pequena vazão $(0,02$ a $1,5 \mathrm{~m}^{3} / \mathrm{h}$ ). A vazão espontânea das fontes termais (Pedro Botelho e dos Macacos) é da ordem de $415 \mathrm{~m}^{3} /$ dia ou 17,3 $\mathrm{m}^{3} / \mathrm{h}$. O reduzido número de poços existentes (em número de 15), com profundidade de 60 a $216 \mathrm{~m}$, tem em geral níveis Me água rasos $(1-5 \mathrm{~m})$, e vazões variando de 7 a $15 \mathrm{~m}^{3} / \mathrm{h}$, com vazões específicas muito baixas $\left(0,08\right.$ a $\left.0,65 \mathrm{~m}^{3} / \mathrm{h} / \mathrm{m}\right)$.

Essa baixa produtividade reflete unicamente as condições hidrogeológicas locais; na sua grande maioria, esses poços foram perfurados em locais pouco propícios, deslocados dos lineamentos estruturais e captando fraturas secundárias de menor permeabilidade. No seu conjunto, a área estudada apresenta um acentuado grau de fraturamento, com potencial hídrico subterrâneo relativamente elevado, como demonstram o grande volume de restituição aos rios e a elevada infiltração. Poços convenientemente locados, segundo os fraturamentos mais extensos e em conexão com a drenagem superficial, poderão fornecer resultados bem mais favoráveis, com maior capacidade de produção.

A origem das águas termais está relacionada a um extenso, e profundo sistema de fraturas abertas, do qual foram identificadas, em aerofotos, pelo menos três direções principais: $\mathrm{N} 14^{\circ} \mathrm{E}, \mathrm{N} 50^{\circ} \mathrm{E}$ e E-W. As emergências das águas termais (Fonte de Pedro Botelho e dos Macacos) situam-se exatamente no ponto de cruzamento destes três sistemas de fraturas.

A COMPOSIÇÃo das ÁGUAS Águas superficiais As águas superficiais têm muito baixo conteúdo de sólidos dissolvidos, em geral menor que $30 \mathrm{ppm}$, podendo alcançar valores de 50 a 80 ppm, no Ribeirão das Antas; são fracamente ácidas a neutras, com pH entre 6 e 7,4, muito brandas, e de composição bicarbonatada ou mista, com pequenas concentrações de cloretos.

As concentrações de ferro podem apresentar-se algo elevadas, acima de 1 ppm; alumínio solúvel é menor que 0,5 ppm; o manganês, em geral, é menor que 0,05 , tendo sido determinado valor de 1,15 ppm no Ribeirão das Antas; e as concentrações de zinco variam de 0,01 a 0,04 ppm. Não foram detectados os metais bário $(<0,02 \mathrm{ppm})$, cobre $(<0,005 \mathrm{ppm})$ e arsênio $(<0,001 \mathrm{ppm})$. As concentrações de fluoreto são baixas, em geral menores que 1,4 ppm a traços.

Determinações de $\mathrm{Ra}^{226}$ em alguns pontos do Ribeirão das Antas, efetuadas pela CETESB em fevereiro de 1985, indicaram valores menores que $0,03 \mathrm{Bg} / \mathrm{l}$. No quadro I, são apresentadas as características químicas das águas superficiais da região. Os dados apresentados constituem apenas uma caracterização geral baseada em amostragem não-sistemática, realizada em diferentes épocas do ano.

Quadrol - Composição das águas superficiais (A) e das fontes de circulação superficial (B), em ppm

Chart 1 - Composition of surface water (A) and surface circulation sources (B) - in ppm

\begin{tabular}{|c|c|c|c|c|c|c|}
\hline & \multicolumn{2}{|c|}{$\begin{array}{l}\text { Valote: } \\
\text { Minfinos }\end{array}$} & \multicolumn{2}{|c|}{$\begin{array}{l}\text { Wilotes } \\
\text { Metinos }\end{array}$} & \multicolumn{2}{|c|}{$\begin{array}{c}\text { Compodfito } \\
\text { Medi }\end{array}$} \\
\hline & A & $\mathbf{B}$ & $\overline{\mathbf{A}}$ & $\mathbf{B}$ & $\mathbf{A}$ & $\mathbf{B}$ \\
\hline Tequperatum (C) & - & 18,4 & $\overline{-}$ & 245 & - & 215 \\
\hline & 6,2 & 5,4 & 7,4 & 6,9 & $=$ & - \\
\hline Conduthidade un mho/cm & 10,50 & 10,0 & 60,0 & 105,5 & 27,7 & 49,8 \\
\hline Reuldno Seco & 4,26 & 27,0 & 27,2 & 100,0 & 15,0 & 56,60 \\
\hline Drreza Tothl etr mg/CaC; & 2,0 & - & 340 & - & 9,4 & 13,33 \\
\hline$a^{2 *}$ & 0,16 & 0,40 & 8,00 & 10,80 & 2,14 & 6,23 \\
\hline $\mathrm{Mg}_{\mathrm{g}}^{2+}$ & 0,13 & 0,20 & 3,36 & 0,92 & 0,88 & 0,60 \\
\hline $\mathrm{Ne}^{+}$ & 0,26 & 0,80 & 091 & 7,50 & 0,64 & 4,30 \\
\hline $\mathbf{k}^{*}$ & 1,19 & 0,80 & 2,27 & 6,50 & 1,53 & 4,15 \\
\hline $\mathrm{HCO}_{3}^{-}$ & 6,10 & 6,10 & 18,30 & 34,70 & 11,48 & 14,47 \\
\hline$\phi_{3}^{2-}$ & $=$ & $=$ & - & $=$ & $=$ & - \\
\hline$c$ & 0,70 & 0,40 & 5,00 & 9,00 & 3,19 & 3,17 \\
\hline $\mathrm{sO}_{4}^{2-}$ & - & 0,5 & $=$ & 1,20 & $=$ & 0,93 \\
\hline FeTotal & 0,11 & $=$ & 20 & 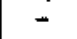 & 0,81 & $=$ \\
\hline $\mathbf{F}$ & 0,10 & 0,08 & 1,41 & 0,38 & 0,44 & 0,18 \\
\hline
\end{tabular}

Águas subterrâneas As águas subterrâneas apresentam características físico-químicas distintas, quer se tratem de águas da zona mais superficial, da zona intermediária ou da zona de circulação profunda. As primeiras são representadas pelas águas de algumas fontes frias e nascentes; a segunda é caracterizada pelas águas extraídas de poços tubulares até uma profundidade de 150 - $200 \mathrm{~m}$; e a última é representada pelas fontes termais (Fig. 1).

AGUAS DE NASCENTES E DE FONTES FRIAS São incluídas, aqui, as águas de inúmeras nascentes difusas, que mantêm os fluxos de base dos principais ribeirões e rios da área, e as fontes pontuais de Poços de Caldas denominadas Fraya, Santo Antônio, Santana 1, Santana 2, São João, Monjolinho, XV de Novembro, XV de Novembro 2, Sete de Setembro e Quisisana Ferruginosa, cujas temperaturas são inferiores a $24^{\circ} \mathrm{C}$.

São águas, em geral, com total de sólidos dissolvidos um pouco mais elevado que o das águas superficiais, com resíduo seco entre 27 e 100 ppm, e um pouco mais ácidas ( $\mathrm{pH}$ de 5,4 a 6,9). Têm baixo conteúdo de $\mathrm{Cl}^{-} \mathrm{e} \mathrm{SO}^{2-}$, com predomínio do ion bicarbonate, apresentando um pequeno incremento dos valores de dureza e de quantidades aproximadamente equivalentes a dos íons alcalinos $\mathrm{Na}^{+}$e $\mathrm{K}^{+}$em relação aos alcalino-terrosos, $\mathrm{Ca}^{2+}$ e $\mathrm{Mg}^{2+}$. $\mathrm{O}$ conteúdo em fluoreto é baixo, menor que $0,38 \mathrm{ppm}$. O quadro 1 mostra as características químicas gerais destas fontes frias de circulação superficial. 


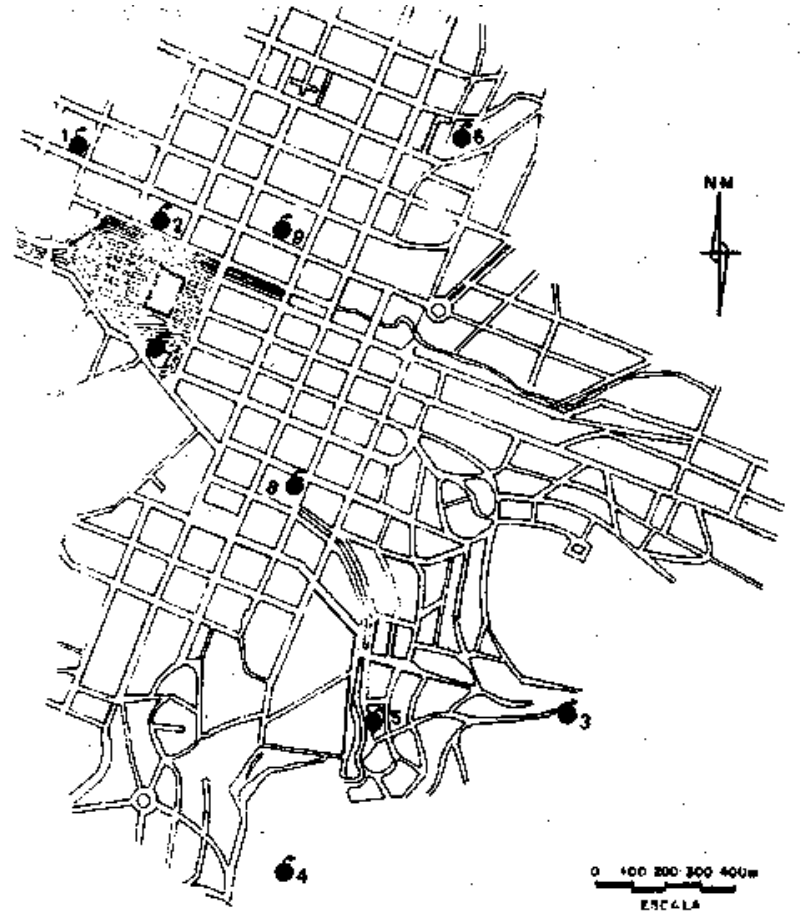

LEGENDA

1. FAMYHA 2- $\left\{\begin{array}{l}\text { SANTAMA } 1 \\ \text { SANTANA } 2\end{array}\right.$

- Sho joR̃o

7 - PEDAO BOTEUK

- Dos MAOACOS

3 - MONJOLINHO

- . SHMASINHA

6 FONTE

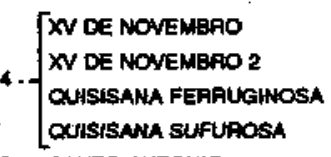

5. SANTO ANTONIO

Figura 1 - Mapa de localização dos pontos de água Figure 1 - Location map for water points

Em relação aos constituintes menores, ocorrem na ordem de traços $(0,001$ a $0,1 \mathrm{ppm})$ os elementos cobre, bário, manganês e zinco; não foram detectados (teores, se existentes, menores que os limites de detecção) o arsênio $(<0,02 \mathrm{ppm})$, *selênio $(<0,006 \mathrm{ppm})$, cádmio $(<0,01 \mathrm{ppm})$, chumbo $(<0,07$ ppm), cromo ( $<0,02 \mathrm{ppm})$ e mercúrio $(<1,0 \mathrm{ppm})$.

Em todas as águas das fontes pontuais citadas não foi detectada a presença de sulfetos $(<0,25 \mathrm{ppm})$, nem urânio $(<0,001 \mathrm{ppm})$, tório $(<0,08 \mathrm{ppm})$ e $\mathrm{Ra}^{226}(<0,03 \mathrm{~Bq} / \ell)$.

Estas fontes são caracterizadas pela presença de gás carbônico livre em concentrações que variam de 7 a 12 ppm.

À exceção das fontes de Santana 2 e XV de Novembro 2, todas as demais contêm teores significativos de $\mathrm{Rn}^{222}(17$ a $109 \mathrm{~Bq} / \ell$ ), conforme mostrado a seguir, segundo determinações efetuadas pela NUCLEBRÁS (1) e BRAILE (Consultec 1970) - (2).

\begin{tabular}{|l|r|c|c|}
\hline & & & 2 \\
\cline { 2 - 4 } & $\mathrm{Bq} / 1$ & Mache & Miche \\
\hline Fonte Fraya & 86 & 6,45 & 7,21 \\
Fonte Santana 1 & 109 & 8,18 & 12,89 \\
Fonte Monjolintso & 54 & 4,05 & 9,60 \\
Fonte XV de Novembro 1 & 81 & 6,08 & - \\
Fonte Sete de Setembro & 17 & 1,27 & - \\
Fonte Quisisana Fertuginosa & -46 & 3,45 & - \\
\hline
\end{tabular}

As variações existentes podem ser devidas a oscilações sazonais do conteúdo de radônio.

As concentrações dos isótopos estáveis (deutério e oxigênio-18) e de trítio constam dos quadros 2 e 3 .

Ouadro 2 - Resultados das analises de oxigênio-18 e deutério de águas subterrâneas de Poços de Caldas

Chart $\mathbf{2}$ - Results of analysis for $\mathbf{0 - 1 8}$ and delterium for groundwater of Poços de Caldas

\begin{tabular}{|c|c|c|c|c|}
\hline Amostra & $\begin{array}{l}\text { Data } \\
\text { Coleta }\end{array}$ & $\begin{array}{l}\text { Identíficaço do } \\
\text { Pontó D'Aqua }\end{array}$ & $5^{18} \mathrm{O}\left(\mathrm{q}_{00}\right)$ & $\mathrm{B}^{2} \mathrm{H}(\mathrm{q})$ \\
\hline 5 & $26 / 11 / 86$ & $\begin{array}{l}\text { Poso PCF-01 } \\
\text { Conjunto Flabitacioatal }\end{array}$ & -7.7 & -34 \\
\hline 6 & $28 / 11 / 86$ & $\begin{array}{l}\text { Popo PCF- } 12 \\
\text { Chíchle Alyorad }\end{array}$ & -8.7 & -60 \\
\hline 9 & $28 / 11 / 86$ & $\begin{array}{l}\text { Popo PCF-3 } \\
\text { Vila Togni }\end{array}$ & $-8,0$ & -54 \\
\hline 10 & $29 / 11 / 86$ & $\begin{array}{l}\text { Fonte PCF-090 } \\
\text { Pedro Botethio }\end{array}$ & $-9,7$ & -66 \\
\hline 11 & $29 / 11 / 86$ & $\begin{array}{l}\text { Fonle PCF-031 } \\
\text { Macicos }\end{array}$ & $-9,6$ & -68 \\
\hline 12 & $28711 / 86$ & $\begin{array}{l}\text { Popo PCF-027 } \\
\text { Fibrica Alcos }\end{array}$ & $-8,1$ & -56 \\
\hline
\end{tabular}

Anàlises realizadas pelo Centro de Energia Nuclear na Agricultura - CENA - USP - Piracicaba - SP

Quadro 3 - Resultados das análises de trítio de águas subterrâneas de Poços de Caldas

Chart 3 - Results of analysis for tritium for groundwater ofr Poços de Caldas

\begin{tabular}{|c|c|c|c|}
\hline Amostra & $\begin{array}{l}\text { Dols } \\
\text { Coleth }\end{array}$ & Identíficação do panto de água & $\begin{array}{c}\text { 3H } \\
\text { (TU) }\end{array}$ \\
\hline 5 & $26 / 11 / 86$ & $\begin{array}{l}\text { Popo PCF-O1 } \\
\text { Conjunito Habitacional }\end{array}$ & $1,4 \pm 0,6$ \\
\hline 6 & $28 / 11 / 86$ & $\begin{array}{l}\text { Poco PCF-12 } \\
\text { Chícara Alvorsdu }\end{array}$ & $1,0 \pm 0,5$ \\
\hline 9 & $28 / 11 / 86$ & $\begin{array}{l}\text { Popo PCF-03 } \\
\text { Vila Togni }\end{array}$ & $4,1 \pm 0,2$ \\
\hline 10 & $29 / 11 / 86$ & $\begin{array}{l}\text { Fonte PCF-030 } \\
\text { Pedro Extelho }\end{array}$ & $1,0 \pm 0,5$ \\
\hline 11 & $29 / 11 / 86$ & $\begin{array}{l}\text { Fonte PCF-031 } \\
\text { Macacose }\end{array}$ & $1,0 \pm 0,5$ \\
\hline 12 & $28 / 11 / 86$ & $\begin{array}{l}\text { Popo PCF-027 } \\
\text { Fábrica Alcoa }\end{array}$ & $1,7 \pm 0,7$ \\
\hline 23 & $17 / 02 / 87$ & $\begin{array}{l}\text { Popo PCF-014 } \\
\text { Clube Aleas }\end{array}$ & $2,6 \pm 0,1$ \\
\hline 24 & $17 / 02 / 87$ & $\begin{array}{l}\text { Fonte PCF-023 } \\
\text { Quisisana Sulfurosa }\end{array}$ & $1,6 \pm 0,6$ \\
\hline 30 & $19 / 02 / 87$ & $\begin{array}{l}\text { Fonte PCF-032 } \\
\text { Sintuzinhos }\end{array}$ & $1,0 \pm 0,5$ \\
\hline 35 & $18 / 08 \beta 87$ & Fonle Monjolinho" & $8,8 \pm 0,3$ \\
\hline 36 & $20108 / 87$ & Fonte Fraya & $7,4 \pm 0,3$ \\
\hline 37 & 29/08/87 & Forve Surtant & $6,5 \pm 0,2$ \\
\hline 38 & $20008 / 87$ & Fonle Qujsisata Fernuginosa & $7,5 \pm 0,3$ \\
\hline 39 & $20 / 08 / 87$ & Córnego Ponte Alla & $7,7 \pm 0,3$ \\
\hline
\end{tabular}

Análises realizadas pelo Centro de Desenwolvimento de Tecnologia Nuclear NUCLEBRAS - Belo Horizonte - MG

AGUAS SUBTERRÂNEAS DA ZONA INTERMEDIARIA São referidas como as águas procedentes de poços tubulares com profundidades de até 150 a $220 \mathrm{~m}$, e temperaturas entre 21 e $26^{\circ} \mathrm{C}$. Elas se diferenciam das águas da zona mais superficial por apresentarem um incremento de sólidos totais dissolvidos (resíduo seco de 55 a 186 ppm), uma elevação gradativa de $\mathrm{pH}$, predominando águas neutras e levemente alcalinas ( $\mathrm{pH}$ variando de 6,2 a 8,4) e aumento das concentrações de bicarbonate e de sódio. Os teores de cloretos mostram apenas uma pequena elevação, enquanto as concentrações de $\mathrm{Ca}^{2+}, \mathrm{Mg}^{2+} \mathrm{e} \mathrm{SO}_{4}^{2-}$ não mostram variações significativas.

As concentrações de fluoreto são variáveis. Na área do Conjunto Habitacional Parque das Nações, as concentrações 
são baixas, com 0,27 ppm de F. Na área em torno da confluência do Ribeirão Várzea das Flores com o Antas, foram determinadas concentrações de 5,58 ppm, e em Poços de Caldas, na Vila Togni e na Chácara Alvorada foram encontrados valores de 6,8 e 3,6 ppm, respectivamente. $O$ valor mais alto detectado foi de $17,5 \mathrm{ppm}$.

As concentrações de ferro total e manganês são inferiores a $0,5 \mathrm{ppm}$ e $0,06 \mathrm{ppm}$, respectivamente, tendo sido determinados valores de $5 \mathrm{ppm}$ de $\mathrm{Fe}$ e 0,11 de $\mathrm{Mn}$ apenas no poço PCF-003 - Vila Togni; o zinco varia de 0,02 a 0,46 ppm, não tendo sido detectados alumínio $(<0,55 \mathrm{ppm})$, bário $(<0,2$ ppm), cobre $(<0,05 \mathrm{ppm})$ e arsênio $(<0,001 \mathrm{ppm})$.

As concentrações dos isótopos estáveis (deutério e oxigênio-18) e de trítio em águas de poços tubulares constam dos quadros 2 e 3 .

No quadro 4 são indicadas as características gerais das águas subterrâneas desta zona intermediária.

Quadro 4 - Composição das águas subterrâneas da zona intermediária $(\boldsymbol{A})$ e das águas termais ${ }^{(1)}(\boldsymbol{B})$, em ppm Chart 4 - Composition for groundwater of mid zone (A) and for thermal water $^{(1)}(\mathrm{B})$ - results in ppm

\begin{tabular}{|c|c|c|c|c|c|c|}
\hline \multirow{2}{*}{$\cdot \cdot \cdot$} & \multicolumn{2}{|c|}{$\begin{array}{l}\text { Vilores } \\
\text { Mhinimos }\end{array}$} & \multicolumn{2}{|c|}{$\begin{array}{l}\text { Vilote } \\
\text { Míxinge }\end{array}$} & \multicolumn{2}{|c|}{$\begin{array}{l}\text { Compoticio } \\
\text { Métia }\end{array}$} \\
\hline & $\overline{\mathbf{A}}$ & $\overline{\mathbf{B}}$ & $\mathbf{A}$ & $\mathbf{B}$ & $\overline{\mathbf{A}}$ & $\overline{\mathbf{B}}$ \\
\hline 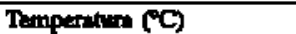 & 21 & 28,8 & 26 & 44 & 227 & 37,5 \\
\hline pH & 6,2 & 9,54 & B.4 & 9,8 & - & - \\
\hline Condutivide em whofem & 44,0 & 585,0 & 243,0 & 1049,0 & 110,40 & 800,79 \\
\hline Realduo Soco & 55,0 & 350,50 & 106,50 & $\sec , 50$ & 127,10 & 519,26 \\
\hline Durom en ppin de $\mathrm{CAOO}_{3}$ & 8,0 & 2,70 & 39,50 & 5,75 & 18,50 & 4,0 \\
\hline $\mathrm{CA}^{*+}$ & 1,60 & 1,14 & 15,04 & 2,65 & 6,07 & 190 \\
\hline $\mathrm{Mg}^{* *}$ & 0,01 & 0,11 & 2,54 & 0,50 & 0,98 & $0, \mathbf{2 3}$ \\
\hline & 6,50 & 138,00 & 4,75 & 214,87 & 32,30 & 189,0 \\
\hline & 1,07 & 4,95 & 40 & 7,20 & 2,95 & 6,2 \\
\hline $\mathrm{HCO}_{3}^{-}$ & 20,74 & 147,72 & 138,30 & $170 ; 90$ & 62,66 & 154,91 \\
\hline$\infty_{3}$ & 0,0 & 66,00 & 12,50 & 146,2 & 12,00 & 133,4 \\
\hline & 0,50 & 2,5 & 12,00 & 5,65 & 4,82 & 3,95 \\
\hline so & 1,00 & 43,14 & 2,70 & 62,50 & 1,36 & 51,90 \\
\hline & 0,27 & 169 & 17,50 & 24,05 & 5,0 & 20,79 \\
\hline sto & $=$ & - & $=$ & 79,10 & $=$ & 29,1 \\
\hline
\end{tabular}

(1) Incluem as fontes de Pedro Botelho (PCF-30), dos Macacos (PCF-31) e Quisisana Sulfurosa (PCF-023)

AGUAS TERMAIS As águas termais são as provenientes das Fontes Pedro Botelho e dos Macacos, localizadas no centro da cidade, cujas características sobre os maiores constituintes constam do quadro 4. São águas hipertermais, alcalinas, bicarbonatadas sódicas e sutfurosas, de acordo com a classificação do Código de Águas Minerais. Diferenciam-se das águas subterrâneas descritas no item anterior, por apresentarem temperaturas de 40 a $44^{\circ} \mathrm{C}$, um aumento acentuado do total de sólidos dissolvidos e de $\mathrm{pH}$ (resíduo seco em torno de 580 ppm e pH entre 9,6 e 9,8), acompanhado de maiores concentrações de carbonates, sódio, sulfetos e fluoretos. Os teores de sulfetos estão em torno de 2,0 ppm, a maior parte presente na forma de íon $\mathrm{SH}^{-}$dissolvido. Apresentam ainda uma quantidade de sílica $\left(\mathrm{SiO}_{2}\right)$ igual a 29,1 ppm e concentrações de fluoretos de $24 \mathrm{ppm}$.

Entre os elementos menores, destacam-se o ferro $(<0,5$ ppm) e o alumínio $(0,10$ a 0,11 ppm), não tendo sido detectados os metais arsênio, zinco, cádmio, cobre, chumbo, manganês e mercúrio. Contém, ainda, radônio $222 \mathrm{em}$ concentrações de 3,7 a 2,7 unidades Mache; o rádio 226 não foi detectado (limite de detecção do método $=0,03 \mathrm{~Bq} / \ell$.

Não foram feitas determinações sobre a concentração e composição de gases nas emergências. Pelas análises existentes e observações in loco, ocorre pequena proporção de gases dissolvidos. Além do radônio, há indicações da presença de nitrogênio na concentração de $15,0 \mathrm{ml}$ a $0^{\circ} \mathrm{C}$ e $760 \mathrm{~mm}$ de pressão atmosférica, conforme determinado pelo Instituto Oswaldo Cruz. Gás sulfídrico, se existente, deve ocorrer em pequena quantidade. As concentrações dos isótopos estáveis deutério e oxigênio-18 e de trítio estão expressas nos quadros 2 e 3.

Ocorrem ainda, na região urbana de Poços de Caldas, duas emergências de águas subterrâneas com características semelhantes às anteriormente descritas, a exceção de sua termalidade: são as Fontes de Sinhazinha e Quisisana Sulfurosa.

A Fonte Sinhazinha é classificada como fonte fria (temperatura de $22,3^{\circ} \mathrm{C}$ ) e a Quisisana Sulfurosa é hipotermal (temperatura $=28,8^{\circ} \mathrm{C}$ ).

Em sólidos dissolvidos, a Fonte Sinhazinha é semelhante às fontes termais $(\mathrm{SD}=574,2 \mathrm{ppm})$, enquanto a Quisisana Sulfurosa é menos mineralizada $(\mathrm{SD}=398,5 \mathrm{ppm})$. Sobre a alcalinidade, conteúdo em sódio, carbonates e fluoretos, assemelham-se às fontes termais. As concentrações de sulfetos são de 2,0 ppm, na Fonte Sinhazinha, e de 0,5 ppm, na Quisisana, sendo mais elevadas as concentrações de radônio (14,9 e 3,9 unidades Maches, respectivamente).

AMBIENTE GEOQUÍMICO Para um melhor entendimento do ambiente geoquímico atual e dos processos que influenciam o quimismo das águas subterrâneas e, em particular, das águas termais de Poços de Caldas, será de interesse analisar alguns aspectos relativos à evolução geológica da região, bem como tecer algumas considerações sobre processos hidrotermais e sobre a gênese e composição de fontes termais, associadas ou não a vulcanismo.

Segundo Ellert (1959), a formação da chaminé alcalina de Poços de Caldas pode ser dividida em seis fases:

1. Soerguimento do embasamento e dos sedimentos, ocasionando falhamentos;

2. Longo período de atividades vulcânicas, quer lentos, com derrames de lavas, quer explosivos, através de tufos e brechas vulcânicas.

3. Subsidência da parte central da câmara magmática, acompanhada de brechificação, milonitização e forte ação tectônica; 4. Reativação com intrusões de natureza nefehnica através das fendas radiais e circulares;

5. Formação dos diques anelares;

6. Intrusão de lujauritos, chibinitos e foiaitos.

É registrada, assim, a existência de focos de vulcanismo e a atuação de processos termo-metamórficos resultantes das intrusões. De ambos os eventos, extrusivos e intrusivos, resultaram rochas ricas em alcali-feldspatos, com um feldspatóide (nefelina) e com subordinada quantidade de anfibólio e piroxênio do tipo rico em $\mathrm{Na}$ - $\mathrm{Fe}$, como a egirina. São rochas que foram cristalizadas na fase final de diferenciação de um magma com pouca sflica, baixa razão $\mathrm{Si} / \mathrm{A} \ell$ e excesso dos metais alcalinos, sódio e potássio.

Os três tipos principais de rochas resultantes (foiaito, tinguaíto e fonolito) mostram composição mineralógica e química muito semelhantes (Quadro 5), sendo diferentes apenas na textura, devido às condições de resfriamento do magma original.

Nessas rochas predominam os minerais anortoclásio, sanidina, nefelina e egirina. Os minerais acessórios mais comuns são analcita, titanita, magnetita, cancrinita, fluorita e zircão.

Não obstante, à semelhança dos tipos de rocha do maciço alcalino, quanto a sua mineralogia e a aparente uniformidade de composição química, uma mais complexa diferenciação e mineralização da área teve lugar devido à própria atividade vulcânica e aos processos hidrotermais e de intemperismo que se seguiram.

A intensidade e os aspectos específicos da atividade hidrotermal em regiões vulcânicas são condicionados por uma complexa combinação de diferentes condições geoló- 
Quadro 5 - Resultados de análises químicas de fonolito e foiaito de Poços de Caldas

Chart 5 - Chemical analysis for fonoiite and foyaite of Focos de Caldas

\begin{tabular}{|c|c|c|c|c|c|c|c|c|c|c|c|c|}
\hline \multirow[b]{2}{*}{ Amotras } & \multicolumn{12}{|c|}{ Conpodesten $x$} \\
\hline & BiO: & ALO & $\mathrm{FoO}$ & Fo & $\mathbf{K O}$ & 사응 & $\infty$ & $\mathbf{M}_{80}$ & $\mathbf{m O}_{2}$ & $\mathrm{P}_{3} \mathrm{O}_{3}$ & $\mathrm{H}_{2} \mathrm{O}^{ \pm}$ & $\mathbf{4} \mathbf{O}^{-}$ \\
\hline Fonolito (1) & 53,66 & 295 & 49 & 279. & 8,3 & 7,18 & 129 & 061 & 0.35 & 0,098 & 1,67 & 0,23 \\
\hline \multirow[t]{2}{*}{ Foinilo (2) } & 53,18 & 21,18 & 3,39 & 0,76 & 8,42 & 7,34 & 1,01 & 1,60 & 0,70 & 0,10 & 1,44 & 120 \\
\hline & \multirow{2}{*}{\multicolumn{12}{|c|}{ 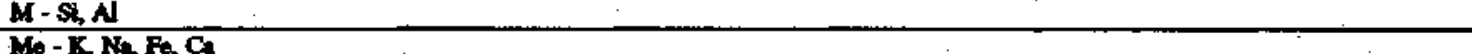 }} \\
\hline \multirow[t]{3}{*}{ Fonoltio (3) } & \multirow{2}{*}{\multicolumn{12}{|c|}{$\frac{\mathrm{Me}-\mathrm{K}, \mathrm{M}, \mathrm{Fe}, \mathrm{Ca}}{\mathrm{T}-\mathrm{Zn}, \mathrm{Sr}, \mathrm{I}, \mathrm{Mh}, \mathrm{Nh}, \mathrm{Rh}, \mathrm{Y}, \mathrm{C}, \mathrm{P}, \mathrm{G}, \mathrm{C}, \mathrm{C}, \mathrm{S}, \mathrm{Zn}}$}} \\
\hline & & & & & & & & & & & & \\
\hline & \multicolumn{12}{|c|}{$\mathbf{M} \cdot \mathbf{3}, \mathbf{A}$} \\
\hline Fotatio (4) & \multicolumn{12}{|c|}{$\mathrm{M} \mathbf{B}-\mathrm{K}, \mathrm{N}, \mathrm{Fe}, \mathrm{C}$} \\
\hline & \multicolumn{12}{|c|}{ 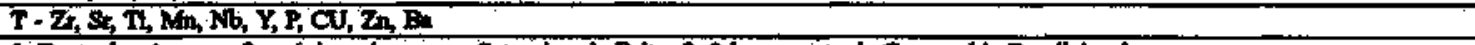 } \\
\hline PROCEDEACAS: & \multicolumn{12}{|c|}{ 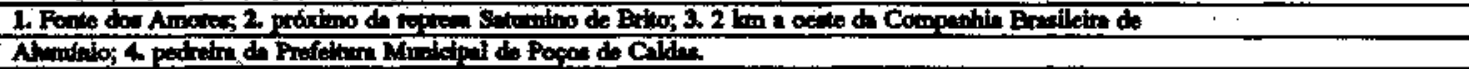 } \\
\hline OBSEXVACOES: & \multicolumn{12}{|c|}{ 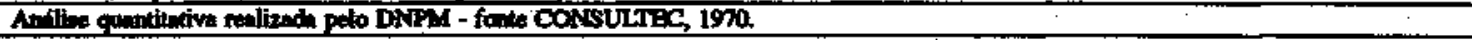 } \\
\hline & \multicolumn{12}{|c|}{ 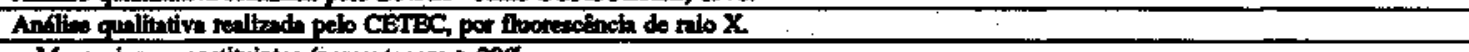 } \\
\hline & \multicolumn{12}{|c|}{ 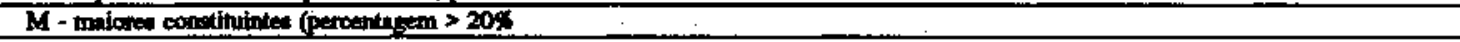 } \\
\hline & \multicolumn{12}{|c|}{ Me - menores contthuintes (percenthetn $<20 \%>1 \%$ ) } \\
\hline & \multicolumn{12}{|c|}{ 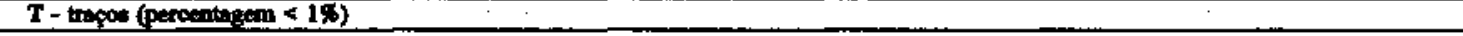 } \\
\hline
\end{tabular}

gicas, geotérmicas e hidrogeológicas, que, podem mostrar grandes variações, ainda que dentro de uma área limitada (Ivanov 1973).

Na área da chaminé alcalina de Poços de Caldas ocorreram profundas modificações do ambiente geoquímico devido aos processos hidrotermais e de meteorização das rochas. As ações hidrotermais desenvolveram diferentes tipos de mineralizações, assim descritas por Gorsky \& Gorsky (1970);

1. Mineralização tipo Agostinho, em zonas de falhamento e brechação em tinguaítos alterados, apresentando-se em um típico network de veios, filmes, acumulações e impregnações irregulares, com uma paragênese de pinta, fluorita e molibdenita uraníferas. A seguinte seqüência de mineralização foi observada:

- pinta e fluorita

- pinta, fluorita e molibdenita

- molibdenita transformada em jordisita

- calcitização, bauxitização, alteração argilosa

- soluções uraníferas, fixação de urânio

- pinta de segunda geração, não-radioativa

- laterização, meteorização, lixiviação parcial de minerais em água.

2. Mineralização em pequenos veios e acumulações de pinta, fluorita e molibdenita (com galena e cassiterita ocasionais) sem radioatividade ou pouco radioativas.

3. Mineralização em rocha feldspática de textura cataclástica, microbrechosa, contendo veios e acumulações irregulares de diferentes agregados: a. rodocrosita rica em ferro, fluorita, pirita e siderita; b. soluções sólidas de Mn e Fe; c. pirita, pirrotita, fluorita, hematita, magnetita, sericita, clorita, traços de urânio e tório

4. Mineralização de caldasito, em veio - composta de oxido e silicato de zircônio - zircão e badelleyíta.

Fujimori (1980), estudando a mineralização uranífera do campo de Agostinho, identificou boa correlação geoquímica do urânio com oito elementos analisados - $\mathrm{ThO}_{2}, \mathrm{ZrO}_{2}, \mathrm{MoO}_{3}$, $\mathrm{A}_{5} \mathrm{O}_{3} \mathrm{SrO}, \mathrm{Y}_{2} \mathrm{O}_{3}, \mathrm{TiO}_{2}$ e $\mathrm{CaO}$. Situação semelhante é observada no Th, que mostra alto grau de correlação com os mesmos elementos, incluindo $\mathrm{K}_{2} \mathrm{O}$ e excetuando SrO. As análises efetuadas indicam a presença dos seguintes elementos:

- Predominantes: $\mathrm{Si}, \mathrm{A} \ell, \mathrm{Ca}$ e Fe

- Teor médio (1\% - 5\%): Ti, Mg, Zr, Na, Sr, S, P, Mo e Ni - Pequeno teor $(0,01 \%$ - $1 \%)$ : V, Y, Th, Nb, As, Pb, Ni, Ba, $\mathrm{Ce}, \mathrm{La}, \mathrm{Cs}, \mathrm{Rb}, \mathrm{Hf}$ e Be

- Em ordem de traços: Ga, Zn, Sn e terras raras.

Os processos de meteorização e intemperismo das rochas do Complexo Alcalino contribuiram também para uma profunda modificação do ambiente geoquímico, resultando numa variada gama de minerais secundários e supergênicos. Estes processos incluem oxidaçâo, especialmente dos minerais ferro-magnesianos (egirina e augita), com transformação em óxidos e hidróxidos de ferro; cloritização, sericitização e caulinização dos feldspatos, analcinizaçãb dos feldspatóides (nefelina), laterização e bauxitização.

Pela sua ampla ocorrência na zona central da estrutura, as rochas alteradas que sofreram um enriquecimento de potássio até grandes profundidades (podendo chegar até a 16\% de $\mathrm{K}_{2} \mathrm{O}$ ) são designadas de "rochas potássicas", cuja origem é atribuída ao hidrotermalismo e à meteorização.

Sobre os principais ambientes de formação de águas termais nas regiões de recente atividade vulcânica, Ivanov (1973) distingue três principais grupos:

I. Águas termais de ambiente oxidante próximo à superfície, em áreas que recebem gases vulcânicos e fluxos termais gerados por estes gases.

II. Águas termais de ambiente redutor profundo, com condições de altas temperaturas devido à proximidades de câmaras magmáticas, com limitado influxo de gases magmáticos e termo-metamórficos.

III. Águas termais de ambiente redutor profundo sob a esfera de influência dos processos termo-metamórficos, sob condições de alta temperatura.

Além desses três tipos, o mesmo autor considera um quarto ambiente de formação, representado pelas águas termais sob condições redutoras em profundidade, sem a influência de processos magmáticos e termo-metamórficos.

Estas águas termais ocorrem, em geral, onde não há manifestação vulcânica recente; termo-metamorfismo desenvolve-se somente a profundidades muito grandes; o regime geotérmico nas formações de rochas superiores $(1 \mathrm{~km}-2 \mathrm{~km})$ é normal ou só fracamente mais alto que o normal.

Nessas regiões, segundo Ivanov (1973), na presença de falhas tectônicas e fraturamentos profundos e abertos, há condições para infiltração profunda de águas meteóricas e para a formação de águas termais nitrogenadas, em meio fissurado, cuja composição não é relacionada a fenômenos magmáticos e termo-metamórficos, mas é exclusivamente determinada por processos de lixiviação das rochas (principalmente vulcânicas e vulcano-sedimentares).

EVOLUĈ̃O FÍSICO-QUÍMICA DAS ÁGUAS - ORIGEM DOS CONSTITUINTES As águas superficiais do Planalto de Poços de Caldas refletem as condições do clima tropical chuvoso, com pequeno déficit hídrico, em uma bacia pequena, de trânsito rápido, na qual domina um solo eluvial resultante de intenso intemperismo. 
Nessas condições, as águas superficiais contêm apenas pequenas quantidades de sais provenientes das próprias precipitações, acrescidas de alguns componentes dissolvidos do solo, já bastante lixiviado. O processo de dissolução é comandado pelo conteúdo de $\mathrm{CO}_{2}$ dissolvido na água. Como este conteúdo é pequeno nas condições de pressão atmosférica, a capacidade de dissolução é reduzida. Em conseqüência, as águas superficiais têm baixa concentração de sais dissolvidos, dominando o bicarbonate de $\mathrm{Na}, \mathrm{Ca}$ e $\mathrm{Mg}$, em quantidades que não ultrapassam, em geral, $30 \mathrm{mg} / \ell$

A partir do momento em que as águas se infiltram, há dissolução de $\mathrm{CO}_{2}$ e de ácidos húmicos provenientes da matéria orgânica do solo, aumentando sua acidez e conseqüente capacidade de dissolução.

As águas subterrâneas da zona superficial, incluindo as nascentes e fontes frias, têm composição influenciada principalmente por este aumento de $\mathrm{CO}_{2}$. São mais ácidas que as águas superficiais, o que permite o ataque às argilas e rochas alteradas, com incorporação de maior quantidade de $\mathrm{Ca}^{2+}, \mathrm{Mg}^{2+}$ e $\mathrm{Na}^{+}$. As concentrações de $\mathrm{C}^{-} \mathrm{e} \mathrm{SO}^{2-}{ }_{4}$ permanecem praticamente inalteradas, aumentando apenas o bicarbonate. São águas de ambiente oxidante, com ausênqa de sulfetos e caracterizadas por uma maior concentração de $\mathrm{Rn}^{222}$ e $\mathrm{CO}_{2}$ livre.

Com o aumento da profundidade, ocorre uma lenta e progresssiva elevação do $\mathrm{pH}$, enriquecimento em $\mathrm{HCO}_{3}^{-}, \mathrm{Na}^{+}$, $\mathrm{SO}^{2-}{ }_{4}$ e em sílica, acompanhado de uma alta concentração de fluoreto. As águas tendem para um ambiente redutor, apresentando aumento de sulfetos e decréscimo da radioatividade.

Estas modificações, que se verificam com o percurso subterrâneo e com o tempo de contato água/rocha, são máximas nas fontes termais de circulação profunda, mas se observa esta tendência desde a zona intermediária até $150 \mathrm{~m}-200 \mathrm{~m}$.

$\mathrm{Na}$ zona intermediária, as águas subterrâneas perdem o caráter ácido e já se apresentam fracamente alcalinas; com um $\mathrm{pH}$ que pode alcançar o valor de 8,4. As concentrações de bicarbonate e de sódio chegam a um máximo de 138 a 43 $\mathrm{mg} / \ell$, enquanto o fluoreto atinge, em alguns locais, níveis de 6,8 ou de até $17 \mathrm{mg} / \ell$

Temperatura das águas As águas subterrâneas da zona de circulação superficial (nascentes e fontes frias) têm temperaturas inferiores a $24^{\circ} \mathrm{C}$ e, embora não sejam feitas medições periódicas, algumas fontes devem apresentar variações sazonais por influência do calor solar, conforme se infere de medidas existentes feitas em diferentes épocas. Araújo (1980) determinou que variações de temperatura pelo efeito sazonal ocorrem até $20 \mathrm{~m}-25 \mathrm{~m}$ de profundidade, com base em perfilagens térmicas de furos de sonda realizadas em diferentes horas e épocas, em cinco áreas da chaminé alcalina de Poços de Caldas.

$\mathrm{Na}$ zona intermediária (até $150 \mathrm{~m}$ - $200 \mathrm{~m}$ de profundidade), as águas procedentes de poços tubulares têm temperaturas que variam de 21 a $26^{\circ} \mathrm{C}$. Por outro lado, a fonte Quisisana Sulfurosa, hipotermal, tem uma temperatura de $28^{\circ} \mathrm{C}$, enquanto as fontes hipertermais de Pedro Botelho e dos Macacos têm temperaturas na emergência de $40-44^{\circ} \mathrm{C}$.

A temperatura das águas nessas profundidades é influenciada principalmente pelo calor interno ou pelo gradiente geotérmico. $\mathrm{O}$ gradiente de temperatura na área estudada varia de 27 a $38^{\circ} \mathrm{C} / \mathrm{km}$ (Araújo 1980), contrastando com os valores do escudo circunvizinho de rochas do embasamento cristalino $\left(9,2\right.$ a $\left.10,4^{\circ} \mathrm{C} / \mathrm{km}\right)$.

As variações existentes dentro da chaminé são atribuídas pelo citado autor ao maior movimento de água subterrânea na área mais intensamente fraturada e mineralizada no centro sul, às reações químicas exotérmicas e, em menor razão, à produção de calor radiogênico.

A temperatura em profundidade das águas termais foi estimada por Hurter et al (1983), em $78,4^{\circ} \mathrm{C}$ a partir do conteúdo em silica.
Com os valores da condutividade térmica $(\mathrm{K})$, da geotemperatura da sílica $\left(\mathrm{T}_{\mathrm{SiO} 2}\right)$, da densidade de fluxo térmico $(\mathrm{q})$ e ainda da temperatura média anual da superfície (b), é possível determinar a profundidade mínima média da circulação ou a profundidade aparente de circulação $(\mathrm{Z})$ da água pela seguinte expressão (Hurter et al 1983).

\section{$2=K \cdot \frac{T_{\mathrm{SO}_{1}}-\mathrm{b}}{\mathrm{q}}$}

Hurter et al (1983) utilizando um valor de $\mathrm{K}=2,6 \mathrm{~W} / \mathrm{m}^{\circ} \mathrm{C}$ correspondente à média de rochas cristalinas $\mathrm{b}=20^{\circ} \mathrm{C}$, $\left(\mathrm{T}_{\mathrm{SiO} 2}\right)=78,4^{\circ} \mathrm{C} \mathrm{e} \mathrm{q}=55 \mathrm{~mW} / \mathrm{m}^{2}$ determinaram uma profundidade aparente de circulação igual a $2.760 \mathrm{~m}$.

Utilizando os valores de $\mathrm{K}=2,2 \mathrm{~W} / \mathrm{m}^{\circ} \mathrm{C}$ e q $=71,0 \mathrm{~mW} / \mathrm{m}^{2}$, fornecidos por Araújo (1980) para a região de Poços de Caldas, e tomando $\left(\mathrm{T}_{\mathrm{SiO} 2}\right)=78,4^{\circ} \mathrm{C}$ e b $=20^{\circ} \mathrm{C}$, é obtida uma profundidade de $1.810 \mathrm{~m}$.

Radioatividade - constituintes gasosos A radioatividade das águas está relacionada à mineralização uranífera da área. Os elementos radioativos encontram-se associados com Th, Zr, Mo, As, Y, Ti, Ca e K, em minerais de urânio e tório, zircão, badelleyíta, monazita, apatita, powelita, fluorita e pirita (Fujimori 1980).

O urânio, tório e rádio estão presentes nas águas subterrâneas em quantidades muito pequenas. O urânio é ligeiramente solúvel. Em meio redutor, precipita-se com facilidade. Águas muito ácidas podem ter quantidades importantes de urânio, como também as águas alcalirias bicarbonatadas, na forma de complexos solúveis. O tório é muito menos solúvel.

Águas que circulam por terrenos uraniferos contêm, em geral, quantidades importantes de $\mathrm{Rn}^{222}$, um gás solúvel que se origina da desintegração do $\mathrm{Ra}^{226}$ e tem um período radioativo muito curto ( $\mathrm{T}=3,8$ dias).

$\mathrm{Na}$ área de Poços de Caldas, as maiores concentrações de $\mathrm{Rn}^{222}$ estão relacionadas às águas das fontes frias da zona mais superficial de circulação rápida, decaindo, com a profundidade, o aumento de salinidade, a temperatura e com a idade da água, em razão do seu curto período de desintegração. As variações de $\mathrm{Rn}^{222}$ entre as fontes termais profundas e as fontes frias da zona superficial parecem resultar, sobretudo, de diferenças de velocidade de circulação da água, antes do que de uma fonte de Rn mais abundante à superfície.

Em Águas da Prata, Szikszay (1981) observou variações sazonais da radioatividade nas águas das fontes, relacionadas também à velocidade de circulação.

Não foram feitas determinações dos constituintes gasosos das águas das fontes no decorrer deste estudo. Várias análises realizadas anteriormente revelam, entretanto, que, além do radônio-222, ocorre $\mathrm{CO}_{2}$ livre nas fontes frias de circulação superficial, proveniente da oxidação da matéria orgânica no solo, em concentrações que variam de 7 a 12 ppm.

Nas fontes termais, a quantidade de gases dissolvidos é muito reduzida; a maior parte constituída de nitrogênio (15 $\mathrm{m} \ell \mathrm{a} \mathrm{O}{ }^{\circ} \mathrm{C}$ e $760 \mathrm{~mm}$ de pressão). Pequena proporção de $\mathrm{H}_{2} \mathrm{~S}$ pode estar presente, a julgar pelo leve odor característico desse gás nas emergências, mas, pelas condições de $\mathrm{pH}$ e Eh, a maior parte do sulfeto está presente na forma do ion HS dissolvido, como se discutirá adiante com mais detalhe.

Carbonates, sódio e pH O aumento de pH e a dissolução de $\mathrm{HCO}_{3}^{-}$e $\mathrm{Na}^{+}$estão relacionados à decomposição dos silicates alcalinos, devido aos fenômenos de hidratação e hidrólise.

O processo de hidrólise dos silicates parece ser um fenômeno rápido, provocando um aumento de $\mathrm{pH}$ por produzir aportes de $\mathrm{OH}^{-}$.

A presença de $\mathrm{CO}_{2}$ dissolvido favorece a hidrólise de carbonatos e de silicatos. Se o contato água/rocha é prolongado, 
quando o $\mathrm{CO}_{2}$ deixa de impor seu efeito tampão, as águas tomam-se alcalinas. Como produto final, restam o íon $\mathrm{Na}^{-} \mathrm{em}$ solução e minerais argilosos como resíduos sólidos.

As concentrações de $\mathrm{HCO}_{3}^{-}{\mathrm{e} \mathrm{CO}^{2-}}_{3}$ nas águas de circulação profunda, ou seja, nas águas das fontes termais, atingem um máximo de 170,0 e 146,0 ppm, respectivamente, ou o equivalente a 382,6 ppm de $\mathrm{CaCO}_{3}$.

Concentrações dessa ordem podem ser atingidas a partir de $\mathrm{CO}_{2}$ atmosférico dissolvido nas águas de infiltração, desde as camadas do solo. Não há, portanto, razões de se suspeitar ou invocar uma fonte ou subministro de $\mathrm{CO}_{2}$ em profundidade. Se assim ocorre, o $\mathrm{CO}_{2}$ dissolvido desde a superfície segue, progressivamente, com o percurso subterrâneo, no ataque aos silicates, incorporando $\mathrm{Na}^{+}$e pequenas quantidades de $\mathrm{Ca}^{2+}$ e $\mathrm{Mg}^{2+}$ até ser consumido totalmente, atingindo a cifra limite em torno de $382,6 \mathrm{ppm}$ de $\mathrm{CaCO}_{3}$ equivalente. Se não há fonte profunda de $\mathrm{CO}_{2}$, este deixa de atuar como tampão a partir de determinado momento; a água perde sua ação dissolvente e o pH da solução sobe, atingindo valores entre 9 e 10.

Silica A presença de silica nas águas termais (concentração de 29,1 ppm) está relacionada à temperatura e o pH, e sua origem deve-se ao próprio processo de alteração das rochas alcalinas.

A hidrogeoquímica da sflica não está de todo esclarecida. Acredita-se que a maior parte da sflica nas águas subterrâneas está como $\mathrm{SiO}_{4} \mathrm{H}_{4}$, em parte dissolvida e em parte coloidal.

As águas fortemente básicas podem ter quantidades importantes de silica iônica, que, por si, já contribuem também à alcalinidade da água. A maioria das águas naturais têm de 1 a 40 ppm de $\mathrm{SiOz}$, podendachegar a até 100 ppm em águas bicarbonatadas sódicas (Custódio \& Llamas 1976). Foumier (1975), estudando a sílica em águas termais, considera que a calcedônia, antes do que o quartzo, controla o conteúdo de sílica dissolvida em aqüíferos com temperaturas abaixo de $100^{\circ} \mathrm{C}$. A forma monomérica é dominante na maioria das fontes quentes. Em águas termais neutras e alcalinas, a sflica monomérica polimeriza rapidamente para espécies cíclicas, sob resfriamento abaixo de $100^{\circ} \mathrm{C}$.

Sulfates e sulfetos Com o objetivo de se verificar a tendência do ambiente em relação à oxidação-redução, e a estabilidade de determinados constituintes iônicos, foram feitas algumas medidas de potencial redox (Eh) em águas de fontes e poços. A figura 2 mostra os valores encontrados em um diagrama $\mathrm{Eh} \times \mathrm{pH}$.

O gráfico indica clara evolução de um ambiente oxidante, fracamente ácido a neutro na zona superficial, para um ambiente redutor básico nas águas de circulação profunda.

$\mathrm{Na}$ zona superficial, com a presença de oxigênio livre, prevalecem as condições para oxidação de sulfetos.

A oxidação produz íons hidrogênio e aumenta a agressividade das águas, tornando-as ácidas, favorecendo a dissolução de carbonates. Um considerável suprimento de oxigênio é necessário para a oxidação de pirita e, portanto, este processo ocorre só na zona superficial, e não em níveis muito abaixo da superfície freática ou onde oxigênio é deficiente.

Nas águas superficiais e nas fontes frias de circulação superficial, na área em tomo de Poços de Caldas, as concentrações de sulfates são, entretanto, muito baixas, o que indicaria a ausência ou reduzida ocorrência de sulfetos, na rocha, em especial da pinta, ao contrário do que se pode esperar na zona de intemperismo das áreas mineralizadas ao sul (Campo de Agostinho, Campo do Cercado).

Na zona de circulação profunda, o ambiente evolui para condições redutoras. Onde há abundante matéria orgânica, a redução de $\mathrm{SO}^{2-}{ }_{4}$ a $\mathrm{S}^{2-}$ pode ser muito importante. Na ausência de matéria orgânica, como é o caso das rochas vulcânicas de

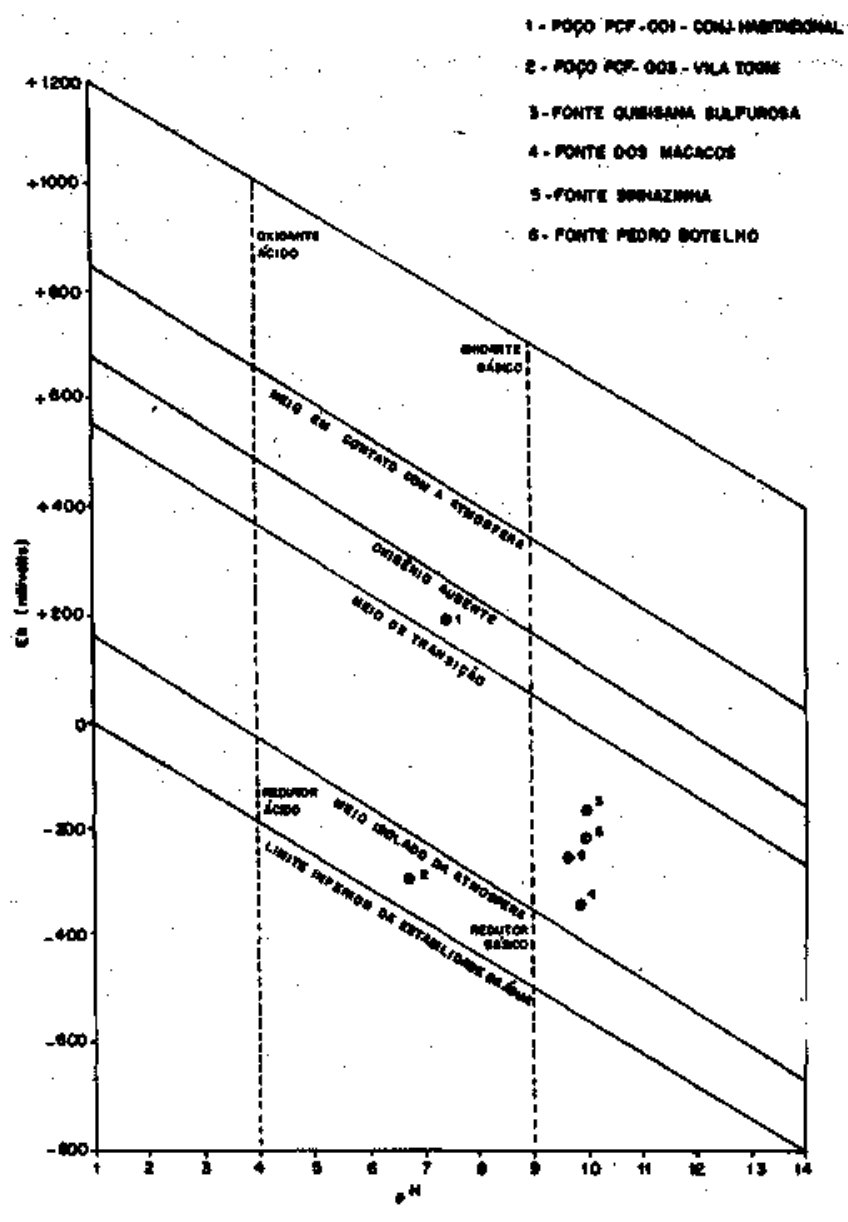

Figura 2 - Diagrama Eh - pH para águas subterrâneas de Poços de Caldas

Figure 2 - Eh - pH diagram for groundwatcr of Poços de Caldas

Poços de Caldas, alguma redução pode ocorrer pela atuação de bactérias. Na redução, há consumo do íon hidrogênio e a água se faz mais alcalina. A redução de $\mathrm{SO}^{2-}{ }_{4}$ a $\mathrm{S}^{2-}$ muito vagarosa, e íons sulfato podem persistir em soluções fortemente redutoras. Por outro lado, uma parte do $\mathrm{S}^{2-}$ formado pode combinar com $\mathrm{Fe}$, abundante nas rochas, e ser fixado como $\mathrm{FeS}$ ou $\mathrm{FeS}_{2}$ insolúveis.

As fontes termais de Pedro Botelho e dos Macacos, juntamente com a Fonte Sinhazinha e Quisisana Sulfurosa têm, ao contrário das fontes frias de circulação mais superficial, concentrações de $\mathrm{SO}^{2-}{ }_{4}$ mais elevadas (de 43 a 77 $\mathrm{ppm}$ ) e teores de $\mathrm{S}^{2-}$ variado de 0,5 a $2,7 \mathrm{ppm}$. Isto indica uma área de recarga e um percurso subterrâneo distintos, onde a zona de intemperismo, talvez mais profunda, teve condições de subministrar sulfates à água por meio dá oxidação de pirita.

Outra conclusão que se pode tirar dos diagramas de $\mathrm{pH}$-Eh é que a maior parte do sulfeto deve estar na forma do íon HS dissolvido, enquanto $\mathrm{o}_{2} \mathrm{~S}$, se existente, deve ocorrer em concentração muito reduzida.

Fluoretos Os processos geológicos que atuaram na formação do complexo alcalino de Poços de Caldas - intrusão alcalina, atividade vulcânica e fase hidrotermal - foram muito favoráveis para uma ampla disseminação de minerais contendo flúor.

O fluoreto ocorre na chaminé alcalina de Poços de Caldas, disseminado nas rochas de modo generalizado, e, em maiores concentrações, nos veios e fissuras preenchidos por soluções hidrotermais. O mineral mais abundante é a fluorita, seguido 
de fluorapatita, ocorrendo também em silicates complexos como lavenita, apofüita e rinkita, e em hidrofosfatos de Aí com F (wavellita) (Gorsky \& Gorsky 1970).

Pelo exposto, verifica-se que o enriquecimento em fluoreto das águas subterrâneas com a profundidade deve-se à dissolução da própria rocha e do material das paredes das fraturas, na qual o aumento de temperatura da água contribui para intensificar o processo de solubilização.

Isótopos estáveis - deutério e oxigênio-18 As concentrações dos isótopos estáveis deutério $\left(\mathrm{D}\right.$ ou $\left.{ }^{2} \mathrm{H}_{1}\right)$ e oxigênio-18 $\left({ }^{18} \mathrm{O}\right)$ foram determinadas em seis amostras de água subterrânea e comparadas com as variações que ocorrem nas águas de chuva. Os resultados são expressos pelo desvio

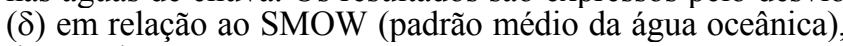
de acordo com a expressão

\section{$\delta=\frac{\text { Amon }}{\text { Asmow }}$}

na qual A é concentração em D ou $\mathrm{O}-18$ expressa em D/H ou em $\mathrm{O}-18 / \mathrm{O}-16$. As variações isotópicas de águas de chuva foram extraídas do trabalho de Szikszay (1981) para a área de Águas da Prata, São Paulo, referente aos anos de 1978 e 1979. No quadro 2, estão os resultados analíticos e, na figura 3 , relação $\delta^{18} \mathrm{O} / \delta \mathrm{D} \%$ das águas subterrâneas e das águas de chuva.
A análise dos resultados expressos na figura 3 , ainda que preliminar, pois se baseia em um número pequeno de determinações, permite apresentar as seguintes considerações:

- A composição isotópica das águas de chuva em Águas da Prata não (teve apresentar diferenças acentuadas em relação a Poços de Caldas, já que dista apenas $22 \mathrm{~km}$ a nordeste (pequena diferença da latitude). Pela altitude (350 $\mathrm{m}$ mais elevada que Aguas de Prata), pode-se esperar chuvas algo mais leves.

- A relação $\delta^{18} \mathrm{O} / \delta \mathrm{D}$ nas águas de chuva da área é definida por uma reta de equação $\delta=8,9 \delta^{18} \mathrm{O}+20$, conforme determinado por Szikszay (1981).

- Observa-se uma tendência normal de chuvas mais leves no período de inverno (maio - junho - julho) e de chuvas mais pesadas nojyerão (outubro - novembro).. O gráfico das médias mensais de $\delta^{18} \mathrm{O}$ (Fig. 3) expressa também estas diferenças estacionais das chuvas da região. Os desvios mais acentuados das chuvas de outubro - novembro (início do período chuvoso) parecem refletir variações de intensidade e duração das chuvas ou intercâmbio isotópico.

- Verifica-se completa correspondência entre as concentrações isotópicas das águas subterrâneas e os Valores médios das águas de precipitação local, indicando que não houve, praticamente, fenômenos de evaporação intensa, à superfície, e que a recarga ocorre principalmente nos meses de novembro a março.

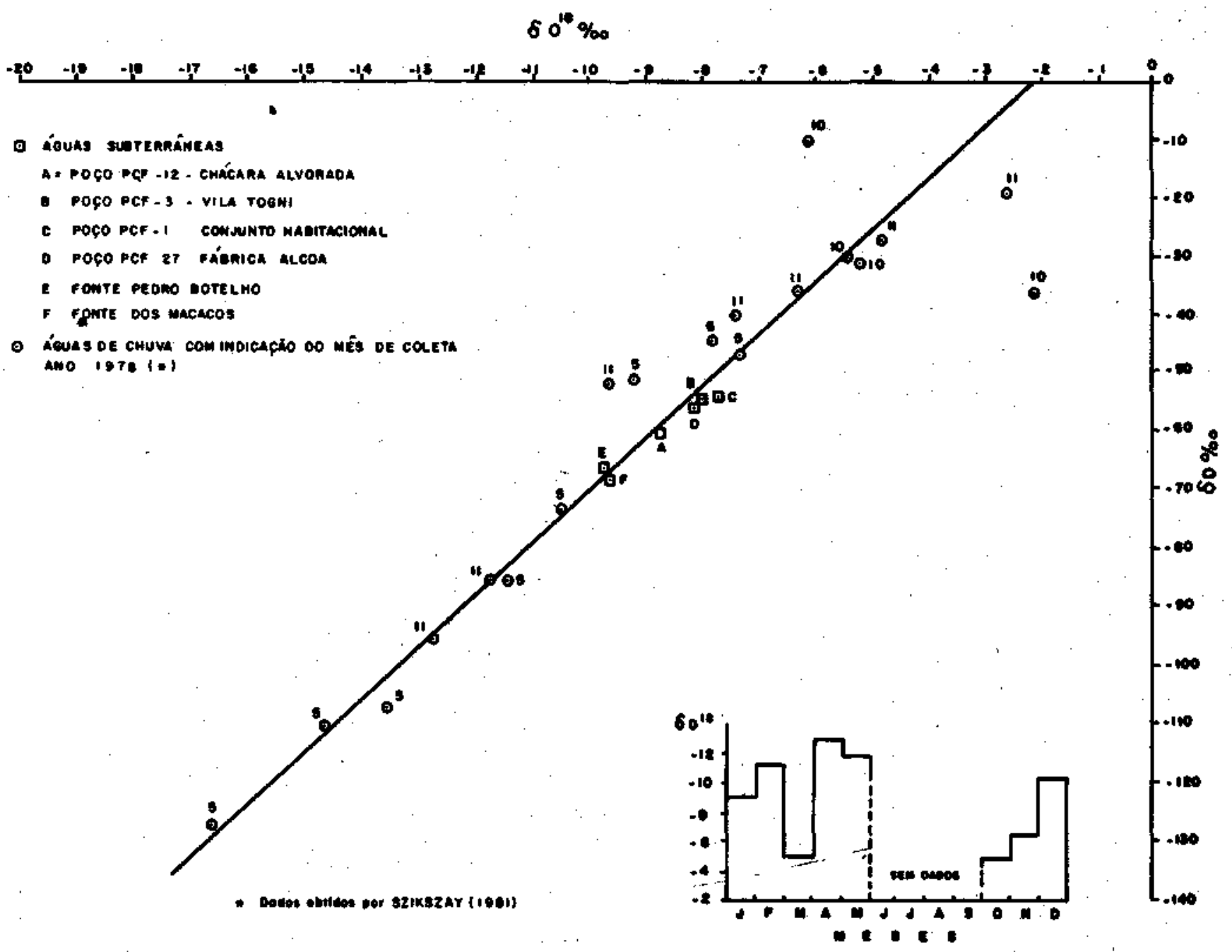

Figura 3 - Relações $\delta \mathrm{O}^{18} / \delta \mathrm{O}^{16}$ em águas de chuva e águas subterrâneas

Figure $3-0^{18} / 0$ relation for rain water and groundwater 
- Para as águas das fontes termais, verifica-se que, ao contrário do que se poderia esperar, elas apresentam-se algo mais leves que as águas subterrâneas da zona intermediária. Com efeito, os materiais sólidos em profundidade, em zonas aquecidas, apresentam concentração de ${ }^{18} \mathrm{O}$ anormalmente elevada. A água em contato com estes materiais apresenta, em geral, uma concentração de ${ }^{18} \mathrm{O}$ superior ao normal, devido ao intercâmbio isotópico entre o oxigênio da água e o da rocha. Aportes de vapor profundo em áreas geotermais podem ter um valor de $\delta^{18} \mathrm{O}$ elevado. Os baixos valores de $\delta^{18} \mathrm{O}$ nas águas termais parecem indicar ausência desses aportes de vapor. Poderiam indicar, também, trocas de ${ }^{18} \mathrm{O}$ da água por $\mathrm{O}^{16}$ da rocha; ou ainda que a recarga destes reservatórios termais seria influenciada pela infiltração nas zonas mais elevadas das serras circundantes com chuvas mais leves.

Trítio As concentrações de T em 14 amostras de águas subterrâneas da área constam do quadro 3. As concentrações médias anuais das precipitações e as médias do período outubro - abril, referentes às estações de Brasília e Rio de Janeiro, constam do quadro 6. Essas estações fazem parte da rede mundial de controle estabelecida pela AIEA, em colaboração com a OMM.

Quadro 6 - Concentrações de trítio nas precipitações de Brasília e Rio de Janeiro

Chart 6 - Concentrations of tritium in rainfalls taken in Brasilia and Rio de Janeiro

\begin{tabular}{|c|c|c|c|c|}
\hline \multirow[b]{3}{*}{ Ano } & \multicolumn{4}{|c|}{ Conectrocio de Trfio (U.T) } \\
\hline & \multicolumn{2}{|c|}{ Batefin } & \multicolumn{2}{|c|}{ Rib do Inetito } \\
\hline & Mádiq & Perfodo & Madn & Perlodo \\
\hline 1955 & $3 ; 7$ & $=$ & 3,0 & - \\
\hline 1956 & 12,3 & - & 10,0 & - \\
\hline 1957 & 8,1 & - & 6,6 & - \\
\hline 1958 & 40,3 & - & 32,7 & - \\
\hline 1959 & 47,8 & * & 38,8 & - \\
\hline 1960 & 12,5 & - & 10,1 & - \\
\hline 1961 & 13,1 & - & 10,7 & \\
\hline 1962 & 76,7 & - & 62,3 & \\
\hline 1963 & 252,2 & $=$ & 204,6 & - \\
\hline 1964 & 152 . & - & 123 & - \\
\hline 1965 & 37,4 & 45 & 36,3 & 40 \\
\hline 1966 & $\mathbf{4 0 , 4}$ & 40,8 & 27,2 & 28,9 \\
\hline 1967 & 30,9 & 30,2 & 19,5 & 21,1 \\
\hline 1968 & 33,7 & 31,5 & 24,3 & 21 \\
\hline 1969 & 23,9 & 26,3 & 19,5 & $19 ; 9$ \\
\hline 1970 & 22,7 & 20,6 & 24 & 22,4 \\
\hline 1971 & 20,1 & 209 & 17,7 & 16,4 \\
\hline 1972 & 15,3 & 17,7 & 16,3 & 16,2 \\
\hline 1973 & 15,6 & 14,8 & 11,2 & 12,1 \\
\hline 1974 & 15,9 & 17,0 & 12,0 & 12,7 \\
\hline 1975 & 13,1 & 14,4 & 11,4 & 12,2 \\
\hline 1976 & 11,8 & - & 9.4 & - \\
\hline 197 & 10,8 & - & 8,6 & - \\
\hline
\end{tabular}

Por estes valores de concentração de T nas precipitações do período de 1955 a 1977, é possível estimar, com boa aproximação, as concentrações nesse período para a área de estudo, o que permite verificar tratar-se de águas "antigas", anteriores ao período de explosões termo-nucleares, ou "recentes".

Calculando as concentrações atuais para cada um dos valores anuais expressos no quadro 6 pela fórmula $C_{t}=6 \exp$ $(-0,6931 / 12,26)$, é possível verificar que águas com menos de 1 UT são anteriores a 1955, ou que se trata de águas antigas $(\mathrm{UT}=0)$ com uma proporção muito pequena de águas recen- tes. Águas com concentrações maiores que 4 - 5 UT seriam posteriores a 1958 .

Os resultados obtidos na área de estudo mostram que as águas termais do Grupos Pedro Botelho e dos Macacos, bem como a da Fonte Sinhazinha, são águas antigas com mais de 30 - 40 anos. As águas de Fonte Quisisana e as procedentes dos poços PCF-12 (Chácara Alvorada), PCF-27 (Fábrica Alcoa) e PCF-14 (Clube Alcoa), com valores de 1,4 a 2,6 UT, são também provavelmente águas antigas anteriores a 1958, embora possam representar águas muito antigas com uma pequena proporção de mistura de águas recentes. Pode-se afirmar, com segurança, que não se trata de águas posteriores a 1961 .

Apenas a água do poço PCF-03 - Vila Togni apresentou maior concentração de T $(4,1 \mathrm{UT})$, podendo representar maior proporção de mistura com águas mais recentes.

As águas das nascentes e fontes frias, por outro lado, são águas recentes (valores de T superiores a 6,5 UT), o que mostra clara concordância com as inferências hidrogeológicas e hidroquímicas. Os resultados/das análises de trítio, considerados em conjunto com os/dados dos isótopos estáveis deutério e oxigênio-18, demonstram que as águas termais são águas meteóricas antigas, com idade superior a 30-40 anos; nessa situação, somente a datação pelo método do C-14 poderia definir, com maior precisão, a idade das águas.

Admitindo que estas águas tenham uma idade mínima de 50 anos e considerando que a profundidade mínima média do reservatório (ou profundidade aparente de circulação) seria de $2.700 \mathrm{~m}$, conforme discutido anteriormente, a velocidade média de circulação das águas, desde as áreas de infiltração, seria de $108 \mathrm{~m} /$ ano ou $0,3 \mathrm{~m} /$ dia.

Elementos menores Os constituintes menores das águas naturais, em sua maioria metais, são oriundos quase exclusivamente de sulfetos, óxidos e silicatos complexos que compõem minerais acessórios das rochas.

A análise química de rocha por fluorescência de raios $\mathrm{X}$, realizada pelo CETEC em amostra de foiaito e fonolito, mostra os elementos presentes e, embora qualitativa, dá indicações do percentual conTque estes participam na composição destas rochas. Os resultados, apresentados no quadro 5, mostram uma quase identidade de composição química entre fonolito e tinguaíto, inclusive em relação aos elementos-traços.

Resultados de análises dos constituintes menores em águas superficiais e subterrâneas da área constam do quadro 7. Da observação destes resultados, conclui-se que a concentração dos elementos pesquisados, seja nas águas superficiais, seja nas subterrâneas, são muito baixas, da ordem de décimos a milésimos de ppm e que, na sua maioria, são inferiores aos limites de determinação dos métodos analíticos.

Elementos como As, $\mathrm{Se}, \mathrm{Cd}, \mathrm{Pb}, \mathrm{Cr}, \mathrm{Hg}$, Th, U, Ra não foram detectados nas águas das fontes frias e termais. Outros elementos, presentes nas rochas como traços, tais como $\mathrm{Zr}$, $\mathrm{Sr}, \mathrm{Ti}, \mathrm{Nb}, \mathrm{Ni}, \mathrm{Rb}, \mathrm{Y}$ e $\mathrm{Ga}$, por problemas laboratoriais, não foram pesquisados, mas serão objeto de futuras determinações.

\section{CONCLUSÕES E RECOMENDAÇÕES}

- A origem das águas termais está relacionada a um extenso e profundo sistema de fraturas abertas, do qual foram identificadas pelo menos três direções principais: $\mathrm{N} 14^{\circ} \mathrm{E}, \mathrm{N} 50^{\circ} \mathrm{E}$ e E-W. As emergências das águas termais localizam-se exatamente no ponto de cruzamento ou de interconexão destas três fraturas principais.

- A maior parte do sulfeto está presente na forma do ion HS dissolvido, devido às condições de $\mathrm{pH}$ e Eh.

- Os resultados das análises de trítio, analisados em conjunto com os isótopos estáveis, deutério e oxigênio-18, demonstram que as águas termais são águas meteóricas antigas, com idade superior a 30 - 40 anos. 


\begin{tabular}{|c|c|c|c|c|c|c|c|c|c|c|c|c|c|c|c|c|c|c|c|c|}
\hline \multirow{2}{*}{\multicolumn{2}{|c|}{ IDENTIFICAFAO DOPONTO D'ÁGUA }} & \multirow{2}{*}{\begin{tabular}{|c|} 
DATA \\
DE \\
COLETA \\
\end{tabular}} & \multicolumn{18}{|c|}{ CONSTITUINTES, EM PPR } \\
\hline & & & A1 & F* & Mn & A* & $2 n$ & se & cd & $\mathrm{cos}$ & $\mathrm{Pb}$ & Bo & cravi] & $\mathrm{Ho}$ & $\mathbf{m}$ & $u$ & $2+3 q_{1}$ & $\mathrm{CH}^{-}$ & $\mathrm{NH}_{3}$ & $s^{2}$ \\
\hline \multirow{3}{*}{ 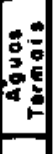 } & Fonm Padro Botetho - PCF - 30 & - & 0,10 & 0,10 & $<0,03$ & $<0,02$ & $<0,006$ & - & $<0,01$ & $<0,01$ & $<0,15$ & $<0,01$ & - & $<0,005$ & - & - & $<0,03$ & $\$ 0,002$ & $<0,05$ & 5,06 \\
\hline & Fonte dos trococoser PCF-3H & $=$ & 0,11 & $<0,0 s$ & $<0,03$ & $<0,02$ & $<0,006$ & - & $<0,01$ & $<0,0 i$ & $<0,13$ & 0,043 & - & $<0,005$ & - & - & $<0,03$ & $<0,002$ & $<0,05$ & 4.93 \\
\hline & Fonte Ouisitsono Sulturoso - PCF -23 & - & $<0,50$ & $<0,5$ & 0,044 & $<0,02$ & 0,023 & $<0,06$ & $<0,01$ & 0,044 & $<0.07$ & $0 ; 043$ & $<0,02$ & $<1,0$ & $<0,00$ & $<0,001$ & $<0,03$ & $<0,000$ & $<r, 0$ & 0,50 \\
\hline \multirow{14}{*}{ 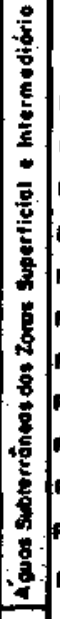 } & Ponte Sinbazintio - PCF- 32 & $\cdot$ & $\cdot$ & $<0,5$ & 9,048 & $<0.02$ & 0,020 & $<0,06$ & $<0,01$ & 0,015 & $<0,0\rangle$ & 0,061 & $<0,02$ & $<1,0$ & $<0,08$ & $<0,001$ & $<0,03$ & $<0,002$ & $<1,0$ & 2,07 \\
\hline & Fonte Froys - PCF-15. & - & - & $<05$ & 0.030 & $<0,02$ & 0,024 & $<0,06$ & $<0,01$ & 0,068 & $<0,07$ & 0,055 & $<0,02$ & $<1,0$ & $<0,00$ & $<0,001$ & $<0,03$ & $<0, \infty 2$ & $<1,0$. & $<0,025$ \\
\hline & Fonto Sontono I- PCF-16 & • & $\cdot$ & $=0,5$ & $0, \infty$ & $<0,02$ & 0.034 & $<0,06$ & $<0,01$ & 0,070 & $<0,07$ & 0.079 & $<0,02$ & $<i, 0$ & $<0,00$ & $<0,001$ & $<0.03$ & $<000$ & $<1,0$ & $\infty, 025$ \\
\hline & Fonte Somana 2 - PCF - 17 & - & $\cdot$ & $<0,5$ & 0,060 & $<0,02$ & 0,104 & $<0,06$ & $<0,01$ & $0,0 \pi$ & $<0,07$ & 0,074 & $<0,02$ & $<1,0$ & $<0,00$ & $<0,00$ & - & $<0, \infty 02$ & $<1,0$ & $<0,025$ \\
\hline & Fonte thonjolidine - PCF - It & $\cdot$ & - & $<0,5$ & 0,034 & $<0,8<\mid$ & 0,023 & $<0, \infty$ & $<0, \alpha$ & 0,080 & $<0,07$ & 0,060 & $<0,02$ & $<1,0$ & $<0,08$ & $<0,001$ & $<0,03$ & $<0,002$ & $<i, 0$ & $<0,085$ \\
\hline & Fint XV et Novembro 1 - PCF-19 & - & - & $<0,5$ & 0,054 & $<0,02$ & 9080 & 20,06 & $<0,01$ & 0,065 & $<0,07$ & 0,058 & $<0,02$ & $<t, 0^{\circ}$ & $<0,00$ & $<0,001$ & $<0,03$ & $<0,000$ & $<1,0$ & 00,028 \\
\hline & Fonie XV de Alovominro 2 - PCF -20 & $\cdot$ & - & $<0,5$ & 0.041 & $<0,02$ & 0,079 & $<0,06$ & $\infty, 01$ & 0,076 & $<0,07$ & 0.061 & $<0,02$ & $<1,0$ & $<0,0$ & $<0,001$ & - & $<0,002$ & $<1,0$ & $-0,02$ is \\
\hline & Fon 1e VII de soltembro - PCF-2I & - & - & $<0,5$ & 0,057 & $<0,02$ & 0,03 & $=0,06$ & $=0.01$ & 0,070 & $<0,0\rangle$ & 0,080 & $<0,02$ & $<1,0$ & $<0, \infty$ & $<0,001$ & $<0,03$ & $<0, \infty<$ & $<1,0$ & $x_{0,025}$ \\
\hline & Fonte Owsiecno Farruginoso - PCF-22 & $\cdot$ & - & $<0,5$ & 0,043 & $<0,02$ & 0,022 & $<0,06$ & $\infty 0,01$ & 0,054 & $<0,07$ & 0,057 & $<0,02$ & $<1,0$ & $<0,00$ & $<0,001$ & $<, 03$ & $<0,002$ & $<1,0$ & $-\infty, 023$ \\
\hline & Pofe conjunto notitectonol - PCF - Ot & $28 / 11 / 86$ & $=0,50$ & 0,17 & $<0,05$ & $<0, \infty, 1$ & 0.02 & - & $\therefore$ & $<0,05$ & - & $<0,20$ & - & - & $\sim$ & - & - & - & - & - \\
\hline & Pope vilo Togni - ACF.03 & $28 / 11 / 86$ & $<0,10$ & 5,00 & 0,11 & $-0,000$ & 0,10 & - & - & $<0,05$ & - & $<0,20$ & - & - & - & $=$ & - & - & - & $=$ \\
\hline & Popo Fúorios Alood - PCF- 27 & $28 / 11 / 86$ & $<0,50$ & 0,16 & $<0,05$ & $<0,001$ & 0,46 & - & $=$ & $<0,05$ & $<0,01$ & $=0,20$ & - & - & - & - & $=$ & - & - & $\because$ \\
\hline & Pofto Chicens Avoredo - PCF- 12 & $29 / 11 / 86$ & $<0,50$ & $0, n$ & $<0,05$ & $<0,001$ & 0,04 & - & $=$ & $<0,05$ & - & $-0,20$ & - & - & - & - & - & - & - & $\therefore$ \\
\hline & Poge CINto Alcoe - PCF - 14 & $17 / 02 / 87$ & $<0,50$ & 0,44 & 0,06 & $<0,001$ & 005 & - & - & $<0,05$ & - & $=0,20$ & - & - & - & - & - & - & - & $=1,0$ \\
\hline & Anoirdo do Cipá - E : 24 & $18 / 02 / 87$ & $=0,50$ & 1,28 & $<0,05$ & $<0,001$ & 0,02 & - & - & $<0,05$ & $<0,01$ & $=0,20$ & - & - & - & $=$ & - & - & - & - \\
\hline 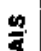 & 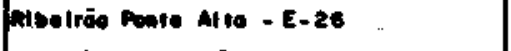 & $18 / 02 / 87$ & $<0,50$ & 0.20 & $<0,05$ & $<0,001$ & 0,01 & - & - & $<0,05$ & $<0,01$ & 20,20 & $=$ & - & - & - & - & - & - & - \\
\hline 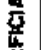 & 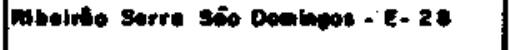 & $18 / 02 / 67$ & $<0,50$ & 0,11 & $<0,05$ & $<0,001$ & 0,03 & - & - & $<0,05$ & $<0,01$ & $<0,20$ & - & - & - & - & - & - & - & - \\
\hline$\frac{\pi}{3}$ & atieniriso den Antes - E - 47 & $18 / 02 / 87$ & $<0,50$ & 0,49 & 1,15 & $<0,001$ & 0,04 & - & - & $\infty 0,05$ & $<0,01$ & $-0,20$ & - & - & - & - & - & $=$ & - & - \\
\hline$\stackrel{2}{3}$ & 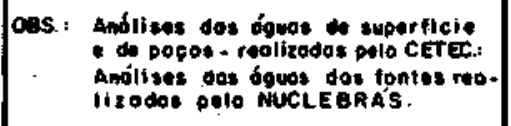 & & & & & & & & & & & & & & & & & & & \\
\hline
\end{tabular}


- Os processos geológicos que atuaram na formação do Complexo Alcalino - intrusão alcalina, atividade vulcânica e fase hidrotermal - foram muito favoráveis para ampla disseminação de minerais contendo flúor. O enriquecimento em fluoreto, das águas subterrâneas, com a profundidade deve-se à dissolução da própria rocha e dos materiais das paredes das fraturas, no qual o aumento de temperatura da água contribuem para intensificar o processo de solubilização

- Recomenda-se estender a pesquisa de constituintes menores das águas, incluindo, em especial, alguns elementos associados à mineralização da área, os quais não puderam ser determinados nesta etapa dos estudos. Sugere-se, também, o prosseguimento dos estudos de datação das águas, pelo método do carbono-14.

\section{REFERÊNCIAS BIBLIOGRÁFICAS}

ARAUJO, R L C. 1980. Pesquisa geotermal na Chaminé Alcana de Pocos de Caldas. In: CONOR. BRAS. GEOL., 31. Camboriú, 1980. Anais... Camboriú, SBG. p. 1059-1074.

BEMOTTO, D.M. \& FUJIMORI, K. 1984. A geoquímica do urânio nos aqüíferos de Águas da Prata. In: COMO BRAS. GEOL., 33. Rio de Janeiro, 1984. Anais... Rio de Janeiro, SBG.

CONSULTEC 1970. Plano de desenvolvimento integrado de Poços de Caldas. Poços de Caldas, Prefeitura Municipal de Poços de Caldas. (Inédito).

CRUZ, W.B. \& PEIXOTO, C.A.M. 1989. As águas termais de Poços de Caldas, MG - Estudo das interações água-rocha. Rev. Bras, Geoc. 19(1):76-86

CUSTÓDIO, E.G. \& LLAMAS, M.R. 1976. Hidrologia subterrânea, 1 ed. Barcelona, Omega S/A.

ELLERT, R. 1959. Contribuição à geologia do Maciço Alcalino de Poços de Caldas. Bol IG/UFOP, 1(3/4):125-135.

ESCODINO, P.C.B. 1983. Determinação do funcionamento hidráulico dos aqüíferos através de parâmetros químicos. Projeto Pesquisa e Desenvolvimento de Métodos e Técnicas de Recursos Naturais - Bacia do Alto São Francisco e Parte Central da Área Mineira da SUDENE. Belo Horizonte, CETEC. 169 p. (Inédito).

FOURNIER, R.O. 1973. Silica in thermal water: laboratory and field investigation. In: SYMP. HIDROGEOCHEM. BIOGEOCHEM. Tokio, 1973. Proceedings... Tokio, Clarke Company Tokio. v.l.

FUJIMORI, K. 1980. Comportamento geoquímico uranífero no Campo do Agostinho. Pocos de Caldas» MG. In: CONOR. BRAS. GEOL., 31 Camboriú, 1980. Anais... Camboriú, SBG. v.2, p. 1125-1139.

FUJIMORI, K.; SARDELA, I.A.; CALLARI, R. 1980. Distribuição de anomalias radioativas no Morro do Ferro do Complexo Alcalino de
Poços de Caldas, MG. In: CONOR. BRAS. GEOL., 31. Camboriú, 1980, Anais... Camboriú, SBG. v. 2, p. 1140-1148.

GORSKY, V.A. \& GORSKY, E. 1970. Diferentes tipos de mineralização no Planalto de Poços de Caldas - MG. In: CONG. BRAS. GEOL., 24. Brasília, 1970. Resumos... Brasília, SBG. Bol. Esp. 1, p.135-137.

GORSKY, V.A. 1973. Contribuição ao estudo dos diferentes tipos de mineralização no Planalto de Poços de Caldas. In: CONG. BRAS. GEOL., 27. Aracaju, 1973. Resumos... Aracaju, SBG. Boi. Esp. 1, p. 19-21.

HURTER, S.J.: ESTON, S.M.; HAMZA, V.M. 1983. Coleção brasileira dos dados geotérmicos. Série 2 - Fontes termais. 2 v. São Paulo, IPT. (Publicações IPT 1233).

IVANOV, V.C, 1973. Main genetic types and formation proceses of thermae in volcanic and non-volcanic areas. In: SYMP. HIDROGEOCHEM. BIOGEOCHEM. Toki0, 1973. Proceedings... Tokio, Clarke Company Tokio. v. 1, p. 174.

KRAUSKOPF, K.B. 1967. Introduction to Geochemistry. Tokyo, Kogakusha Company.

PLATA, A.B. 1972. Isotopes em Hidrologia. Madrid, Editorial Allambra. SZIKSZAY.M. 1981. Hidrogeoquímica das fontes de Aguas da Prata. Estado de São Paulo. Origem, classificação e caracterização. 2v. São Paulo, IG/USP.
MANUSCRITO A601

Recebido em 23 de maio de 1989

Revisão do autor «m 12 de outubro de 1990 Revisão aceita em 12 de outubro de 1990 